\title{
A pharmacokinetic study of diclofenac sodium in rats
}

\author{
JING YUAN, HE MA, NANNAN CEN, AI ZHOU and HENGXUN TAO \\ College of Animal Science, Yangtze University, Jingzhou, Hubei 434025, P.R. China \\ Received June 9, 2017; Accepted July 5, 2017
}

DOI: $10.3892 /$ br.2017.942

\begin{abstract}
The aim of the present study was to examine the pharmacokinetics of a single intravenous injection (i.v.) and oral administration (p.o.) of diclofenac sodium (DIC) in Sprague-Dawley (SD) rats. Twelve male SD rats were divided into 2 groups ( $n=6$ per group); one group was injected intravenously with $2 \mathrm{mg} / \mathrm{kg}$ DIC, whereas the other group was lavaged with $2 \mathrm{mg} / \mathrm{kg}$ DIC. Blood samples were collected prior to DIC delivery $(0 \mathrm{~h})$ and $0.033,0.083,0.167$, $0.25,0.5,1,2,4,6$, and $8 \mathrm{~h}$ post-administration. Blood plasma samples were analyzed using liquid chromatography-mass spectrometry (LC-MS/MS) following pretreatment to induce protein precipitation. Pharmacokinetics software was applied to calculate relevant pharmacokinetic parameters using a non-compartmental model. Following i.v. administration of DIC, the terminal elimination rate constant $\left(\lambda_{z}\right)$, apparent terminal elimination half-life $\left(t_{1 / 2}\right)$, area under the concentration-time curve from time 0 extrapolated to infinity $\left(\mathrm{AUCO}_{-\infty}\right)$, clearance $(\mathrm{CL})$, apparent volume of distribution $\left(\mathrm{V}_{\mathrm{z}}\right)$, mean residence time (MRT), and apparent volume of distribution at steady state $\left(\mathrm{V}_{\mathrm{ss}}\right)$ were $0.57 \pm 0.05 \mathrm{l} / \mathrm{h}$, $1.22 \pm 0.11 \mathrm{~h}, 3356 \pm 238 \mathrm{~h} \mathrm{x} \mathrm{ng} / \mathrm{ml}, 0.60 \pm 0.04 \mathrm{l} / \mathrm{h}, 1.05 \pm 0.10 \mathrm{l}$, $1.05 \pm 0.07 \mathrm{~h}$ and $0.63 \pm 0.07 \mathrm{l}$, respectively. Following p.o. administration of DIC, the $\lambda_{\mathrm{z}}, \mathrm{t}_{1 / 2}, \mathrm{C}_{\max }, \mathrm{t}_{\max }, \mathrm{AUC}_{0-\infty}, \mathrm{CL}$, $\mathrm{V}_{\mathrm{z}}$, MRT were: $0.63 \pm 0.12 \mathrm{l} / \mathrm{h}, 1.12 \pm 0.18 \mathrm{~h}, 1272 \pm 112 \mathrm{ng} / \mathrm{ml}$, $0.19 \pm 0.04 \mathrm{~h}, 2501 \pm 303 \mathrm{~h} \mathrm{x} \mathrm{ng} / \mathrm{ml}, 0.81 \pm 0.10 \mathrm{l} / \mathrm{h}, 1.29 \pm 0.12 \mathrm{l}$, and $2.70 \pm 0.18 \mathrm{~h}$, respectively. The pharmacokinetic parameters of i.v. and p.o. DIC in rats show that the drug is rapidly absorbed, distributed, and eliminated.
\end{abstract}

\section{Introduction}

DIC is a non-steroidal anti-inflammatory drug advocated for use in painful and inflammatory rheumatic and certain non-rheumatic conditions. DIC is available in a number of administration forms that can be given orally, rectally, or

Correspondence to: Mr. Hengxun Tao, College of Animal Science, Yangtze University, 88 Jingmi Road, Jingzhou, Hubei 434025, P.R. China

E-mail: taohengxun@163.com

Key words: diclofenac sodium, rat, pharmacokinetics, intravenous injection, oral medication intramuscularly (1). DIC is an inhibitor of cyclooxygenase, and its potency is substantially greater than that of indomethacin, naproxen, and several other agents (2-5). Despite the widespread clinical use of DIC for $>20$ years, there is little published information on its pharmacokinetics in animals, especially in rats. Variations in pharmacokinetic parameters between different animal species are common and mostly related to differences in genetics and/or environmental conditions (6).

The aim of the present study was to determine the pharmacokinetics profile of DIC in rats after intravenous injection (i.v.) and oral administration (p.o.).

\section{Materials and methods}

Drugs and reagents. DIC was purchased from Sigma-Aldrich Co., LLC (Shanghai, China) and served as a control. Naproxen was purchased from Sigma-Aldrich Co., LLC and used as an internal standard. Acetonitrile of HPLC grade was purchased from Merck Chemicals Co., Ltd. (Shanghai, China). Methanol of HPLC grade was purchased from Burdick and Jackson (Morristown, NJ, USA). Ammonium acetate of HPLC grade was purchased from Sigma-Aldrich Co., LLC. Ultrapure water was produced by a Milli-Q Advantage A10 purification system.

Instruments and equipment. The HPLC system was a Shimadzu LC-20AD (Shimadzu, Co., Ltd., Shanghai, China) system consisting of a degasser, a communication bus module, a pump, an autosampler, and a column oven. Mass spectrometric detection was accomplished with an Applied Biosystems Sciex API 3000 mass spectrometer (Applied Biosystems Sciex, Mississauga, ON, Canada) equipped with an electrospray ionization (ESI) source. Analytical software (version 1.4.2; Applied Biosystems/MDS Sciex) was used for data acquisition and processing. The following instruments were also used: WH-861 vortex shaker (Taicang HUALIDA Experimental equipment Co., Ltd., Taicang, China), high-speed refrigerated centrifuge (5810R; Eppendorf AG, Hamburg, Germany), analytical balance [XS205; Mettler-Toledo Instruments (Shanghai) Co., Ltd., Shanghai, China], and Milli-Q Advantage A10 purification system (Millipore Corp., Billerica, MA, USA). The chromatographic column was an Agilent Zorbax XDB-C18 (3.5 $\mu \mathrm{m}, 2.1 \times 50 \mathrm{~mm})$ column.

Experimental animals. Twelve male Sprague-Dawley (SD) rats weighing 231-257 $\mathrm{g}$ were purchased from the Laboratory 
Animal Center of the Zhejiang Academy of Medical Sciences (Hangzhou, China).

\section{Experimental methods}

Solution preparation. A suitable amount of DIC (1 g) was weighed and dissolved in physiological saline (Sinopharm Group Co. Ltd., Shanghai, China) to produce a $1 \mathrm{mg} / \mathrm{ml}$ solution that was used for intravenous and intragastric administration.

Drug delivery and sample collection. Before DIC administration, the rats were fasted for $12 \mathrm{~h}$ with access to drinking water. Six male SD rats were injected with $2 \mathrm{mg} / \mathrm{kg}$ DIC through the tail vein at a dosing volume of $2 \mathrm{ml} / \mathrm{kg}$. Blood ( $1 \mathrm{ml}$ ) was taken from the orbital venous plexus prior to administration of test substances $(0 \mathrm{~h})$ and after $0.033,0.083,0.167,0.25,0.5,1,2,4$, 6 and $8 \mathrm{~h}$. Blood samples were collected in tubes containing K2-EDTA and kept on ice until they were centrifuged at $2,400 \mathrm{x} \mathrm{g}$ for $10 \mathrm{~min}$ at $4^{\circ} \mathrm{C}$ to allow the collection of plasma, which was stored at $-80^{\circ} \mathrm{C}$.

Six male SD rats were lavaged with $2 \mathrm{mg} / \mathrm{kg}$ DIC at a dosing volume of $2 \mathrm{ml} / \mathrm{kg}$. Blood $(1 \mathrm{ml})$ was taken from the orbital venous plexus prior to administration of test substances $(0 \mathrm{~h})$ and after $0.033,0.083,0.167,0.25,0.5,1,2,4,6$ and $8 \mathrm{~h}$. Blood samples were collected in tubes containing K2-EDTA and kept on ice until they were centrifuged at 2,400 $\mathrm{x}$ g for $10 \mathrm{~min}$ at $4^{\circ} \mathrm{C}$ to allow the collection of plasma, which was stored at $-80^{\circ} \mathrm{C}$.

Preparation of calibration standard samples and quality control $(Q C)$ samples. A standard stock solution $(1 \mathrm{mg} / \mathrm{ml})$ of DIC was prepared by dissolving DIC $(10 \mathrm{mg})$ in $5 \mathrm{ml}$ methanol/10 mM ammonium acetate (80:20, v/v). Calibration standard samples were prepared at concentrations of 10, 20, $50,100,500,1,000,5,000$, and $10,000 \mathrm{ng} / \mathrm{ml}$ with the same mixed solvent. QC solutions with low, medium, and high concentrations $(20,500$ and 5,000 $\mathrm{ng} / \mathrm{ml})$ were prepared in the same manner. The standard IS stock solution $(2 \mathrm{mg} / \mathrm{ml})$ of Naproxen was prepared by dissolving Naproxen $(10 \mathrm{mg})$ in $5 \mathrm{ml}$ methanol. The IS working solution $(1,000 \mathrm{ng} / \mathrm{ml})$ was prepared with methanol/10 mM ammonium acetate (80:20, v/v).

Sample preparation. The frozen plasma samples were thawed at room temperature. An aliquot of $5 \mu \mathrm{l}$ of IS solution $(1,000 \mathrm{ng} / \mathrm{ml}$ Naproxen in the mobile phase) was added to a $50-\mu 1$ plasma sample in a microcentrifuge tube. After vortex-mixing for $10 \mathrm{sec}, 200 \mu 1$ methanol was added to the mixture to precipitate proteins. The sample was vortex-mixed for $1 \mathrm{~min}$ and centrifuged at $17,829 \mathrm{x} \mathrm{g}$ at $4^{\circ} \mathrm{C}$ for $20 \mathrm{~min}$. Finally, $100 \mu \mathrm{l}$ of the supernatant was transferred to an injection bottle, which was loaded into an autosampler cabinet, from which a 7- $\mu$ l aliquot was injected into the LC-MS/MS system. Samples with concentrations greater than the maximum standard in the calibration curve were determined following dilution with blank plasma.

LC-MS/MS conditions. The concentration of DIC in plasma was measured using HPLC-MS/MS. The HPLC-MS/MS system was a Shimadzu LC-20AD coupled to an API 3000 triple quadrupole mass spectrometer with an ESI source. The tandem mass spectrometer was operated under multiple reaction monitoring (MRM) using an electro-spray ionization source in negative ion mode. The optimized HPLC-MS/MS conditions were as follows: Collision gas of 10 psi, a curtain gas of 25 psi, a gas 1 of 50 psi, a gas 2 of 50 psi, an ion spray voltage of $-5,000 \mathrm{~V}$, a source temperature of $500^{\circ} \mathrm{C}$, and an entrance potential of $-4 \mathrm{~V}$ for DIC and $-5 \mathrm{~V}$ for the IS (Naproxen). Quantification of $\mathrm{m} / \mathrm{z}, 293.85$ to $\mathrm{m} / \mathrm{z} 249.86$ for DIC and $m / z, 228.67$ to $m / z, 184.71$ for Naproxen was performed in MRM. Chromatograms were integrated with Analyst software (version 1.4.2).

Chromatographic separation was performed on a Zorbax XDB-C18 column $(3.5 \mu \mathrm{m}, 2.1 \times 50 \mathrm{~mm})$. The mobile phase consisted of methanol/10 mM ammonium acetate $(80: 20 \mathrm{v} / \mathrm{v})$ at an isocratic flow rate of $0.3 \mathrm{ml} / \mathrm{min}$. The injection volume was $7 \mu \mathrm{l}$. The run time was $3 \mathrm{~min}$. The temperatures of the analytical column and autosampler were set at 35 and $4{ }^{\circ} \mathrm{C}$, respectively. Under these conditions, the retention times for DIC and Naproxen were 1.63 and 1.54 min, respectively.

The quantification method was shown to be suitable for the determination of DIC in rat plasma. The specificity, sensitivity, linearity, rate of extraction recovery, within-day and between-day precision, stability, and matrix effect of the analytical method conformed to relevant provisions regarding biological sample analysis (7-9).

Statistical analysis. The pharmacokinetic parameters of DIC were analyzed and processed by the non-compartmental model of WinNonlin5.2 software (Pharsight Corporation, Mountain View, CA, USA). The experimental data were presented as mean \pm standard deviation (mean $\pm \mathrm{SD}$ ). The maximum plasma concentration $\left(\mathrm{C}_{\max }\right)$ and time taken to reach $\mathrm{C}_{\max }\left(\mathrm{T}_{\max }\right)$ were estimated directly from the observed plasma concentration-time data. The elimination rate constant $\left(\lambda_{\mathrm{z}}\right)$ was determined by linear regression analysis of the log-linear part of the plasma concentration-time curve. The total area under the plasma concentration-time curve $\left(\mathrm{AUC}_{0-\mathrm{t}}\right)$ was calculated using the linear trapezoidal rule. The AUC from 0 to infinity $\left(\mathrm{AUC}_{0-\infty}\right)$ was calculated as $\mathrm{AUC}_{0-\infty}=\mathrm{AUC}+\mathrm{Ct} / \lambda_{\mathrm{z}}$ (where $\mathrm{Ct}$ was the last plasma concentration measured). The half-life $\left(\mathrm{T}_{1 / 2}\right)$ of DIC was calculated as $T_{1 / 2}=\ln 2 / \lambda_{z}$. The apparent clearance (CL) of DIC was calculated as $\mathrm{CL}=\operatorname{dose} / \mathrm{AUC}_{0-\infty}$. The apparent volume of distribution $\left(\mathrm{V}_{\mathrm{z}}\right)$ of DIC was calculated as $\mathrm{V}=\mathrm{CL} / \lambda_{\mathrm{z}}$.

\section{Results and Discussion}

Plasma concentration and concentration-time curve. After i.v. and p.o. administration of $2 \mathrm{mg} / \mathrm{kg}$ DIC $(\mathrm{n}=12)$ to SD rats, the relationship between the plasma concentration of DIC and time was determined (Table I). The concentration-time curves for i.v. and p.o. DIC are shown in Figs. 1 and 2, whereas the mean concentration-time curves are shown in Fig. 3. The drug concentration in the plasma decreased rapidly after i.v. administration of DIC. After $8 \mathrm{~h}$, the concentration of DIC in the plasma was approximately $10 \mathrm{ng} / \mathrm{ml}$.

Pharmacokinetic study. WinNonlin pharmacokinetic software was used to analyze the plasma concentration of DIC using a noncompartmental model following administration in rats. The pharmacokinetic parameters (after fitting) are shown in Table I. 
Table I. Mean plasma concentration (mean \pm SD) of diclofenac sodium after i.v. (rat 1-6) and p.o. (rat 7-12) administration at a dose of $2 \mathrm{mg} / \mathrm{kg}$.

\begin{tabular}{lcc}
\hline & \multicolumn{2}{c}{ Concentration (ng/ml) } \\
\cline { 2 - 3 } Time (h) & i.v. & p.o. \\
\hline 0.03 & $9413.5 \pm 1276.0$ & $38.7 \pm 12.9$ \\
0.08 & $6197.4 \pm 674.6$ & $418.1 \pm 137.4$ \\
0.17 & $3903.9 \pm 529.4$ & $1195.6 \pm 218.4$ \\
0.25 & $2066.0 \pm 364.5$ & $1019.8 \pm 123.8$ \\
0.5 & $1108.6 \pm 284.6$ & $649.4 \pm 97.2$ \\
1 & $476.6 \pm 65.7$ & $416.4 \pm 96.6$ \\
2 & $391.0 \pm 26.4$ & $402.9 \pm 178.5$ \\
4 & $95.5 \pm 17.5$ & $368.7 \pm 62.7$ \\
6 & $47.2 \pm 9.7$ & $109.8 \pm 29.2$ \\
8 & $10.7 \pm 3.3$ & $31.3 \pm 13.1$ \\
\hline
\end{tabular}

SD, standard deviation; i.v., intravenous; p.o., oral administration.

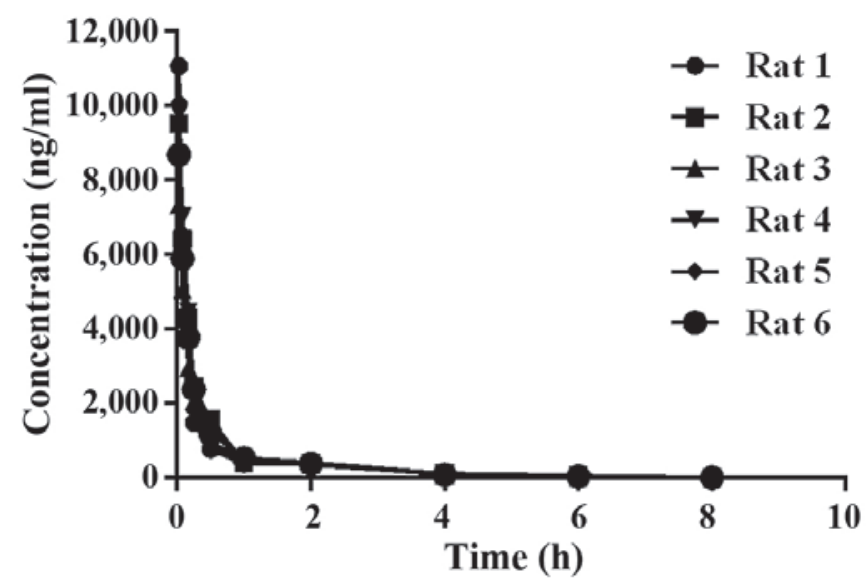

Figure 1. Individual time-concentration curves of diclofenac sodium (intravenous administration of $2 \mathrm{mg} / \mathrm{kg}$ to rat $1-6$ ).

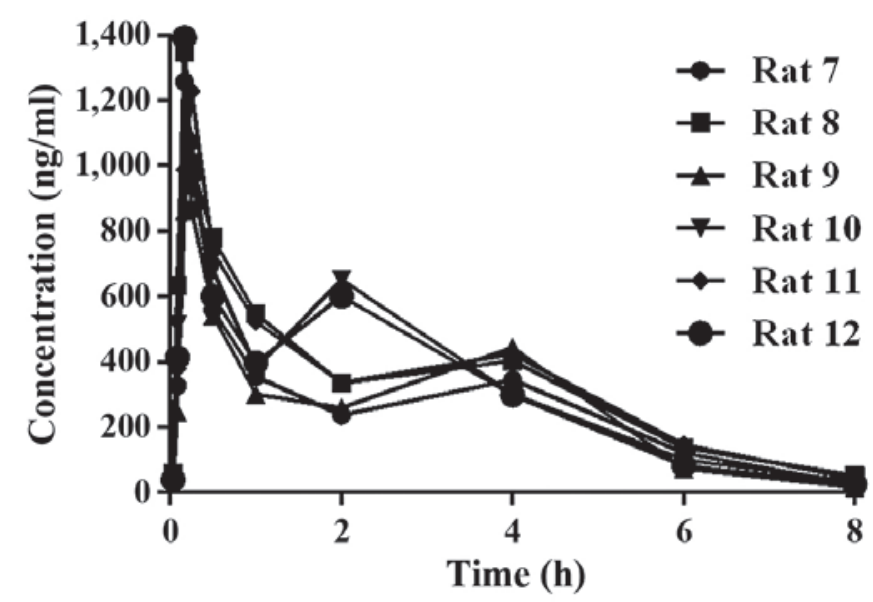

Figure 2. Individual time-concentration curves of diclofenac sodium (administration by lavage at a dose of $2 \mathrm{mg} / \mathrm{kg}$ to rat $7-12$ ).
Table II. Pharmacokinetic parameters (mean \pm SD) of diclofenac sodium in plasma following intravenous and intragastric administration to rats.

\begin{tabular}{lccc}
\hline $\begin{array}{l}\text { Pharmacokinetic } \\
\text { parameters }\end{array}$ & Unit & i.v. & p.o. \\
\hline$\lambda_{\mathrm{z}}$ & $\mathrm{l} / \mathrm{h}$ & $0.57 \pm 0.05$ & $0.63 \pm 0.12$ \\
$\mathrm{t}_{1 / 2}$ & $\mathrm{~h}$ & $1.22 \pm 0.11$ & $1.12 \pm 0.18$ \\
$\mathrm{t}_{\max }$ & $\mathrm{h}$ & & $0.19 \pm 0.04$ \\
$\mathrm{C}_{\max }$ & $\mathrm{ng} / \mathrm{ml}$ & & $1272 \pm 112$ \\
$\mathrm{C}_{0}$ & $\mathrm{ng} / \mathrm{ml}$ & $12449 \pm 2261$ & \\
$\mathrm{AUC}_{0-\mathrm{t}}$ & $\mathrm{h} \mathrm{x} \mathrm{ng} / \mathrm{ml}$ & $3337 \pm 235$ & $2448 \pm 279$ \\
$\mathrm{AUC}_{0-\infty}$ & $\mathrm{h} \mathrm{x} \mathrm{ng/ml}$ & $3356 \pm 238$ & $2501 \pm 303$ \\
$\mathrm{~V}_{\mathrm{z}}$ & $\mathrm{l}$ & $1.05 \pm 0.10$ & $1.29 \pm 0.12$ \\
$\mathrm{CL}$ & $1 / \mathrm{h}$ & $0.60 \pm 0.04$ & $0.81 \pm 0.10$ \\
$\mathrm{MRT}_{\mathrm{V}}$ & $\mathrm{h}$ & $1.05 \pm 0.07$ & $2.70 \pm 0.18$ \\
$\mathrm{~V}_{\mathrm{ss}}$ & 1 & $0.63 \pm 0.07$ & \\
$\mathrm{~F}$ & $\%$ & & $74.4 \pm 6.4$
\end{tabular}

$\mathrm{SD}$, standard deviation; $\lambda_{\mathrm{z}}$, terminal elimination rate constant; $t_{1 / 2}$, apparent terminal elimination half-life; $\mathrm{C}_{\theta}$, initial plasma concentration; $\mathrm{C}_{\max }$, peak plasma level; $\mathrm{T}_{\max }$, time to peak plasma level; $\mathrm{AUC}_{0-\mathrm{t}}$, area under the concentration-time curve from time 0 to the time of the last quantifiable concentration; $\mathrm{AUC}_{0-\infty}$, area under the concentrationtime curve from time 0 extrapolated to infinity; CL, clearance; $\mathrm{V}_{\mathrm{z}}$, apparent volume of distribution; MRT, mean residence time; $\mathrm{V}_{\mathrm{ss}}$, apparent volume of distribution at steady state.

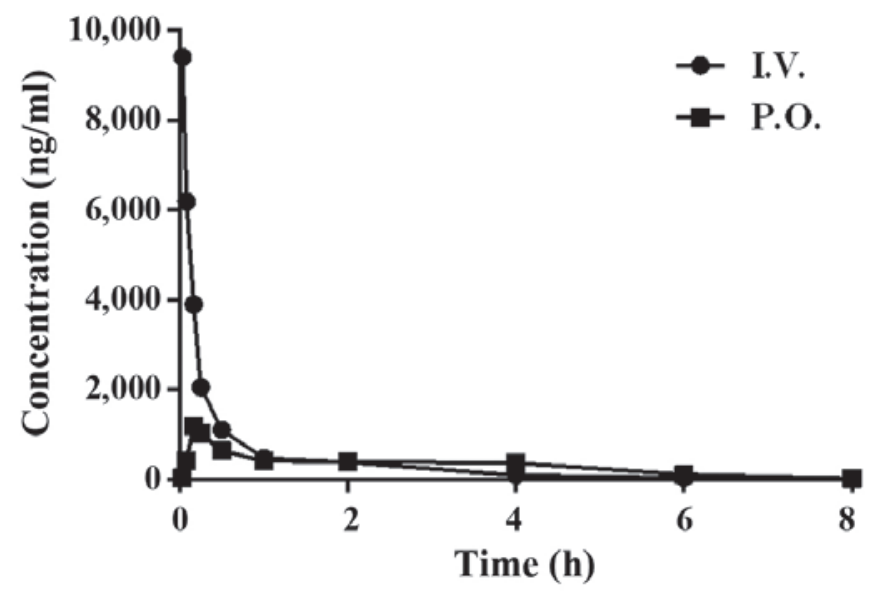

Figure 3. Mean time-concentration curves of diclofenac sodium (administered intravenously and by lavage at a dose of $2 \mathrm{mg} / \mathrm{kg}$ to rat 1-12).

As shown in Table II, the $\lambda_{\mathrm{z}}(0.63 \pm 0.12 \mathrm{l} / \mathrm{h}), \mathrm{t}_{1 / 2}(1.12 \pm 0.18 \mathrm{~h})$, $\mathrm{C}_{\max }(1272 \pm 112 \mathrm{ng} / \mathrm{ml}), \mathrm{t}_{\max }(0.19 \pm 0.04 \mathrm{~h}), \mathrm{AUC}_{0-\infty}$ $(2501 \pm 303 \mathrm{~h} \mathrm{x} \mathrm{ng} / \mathrm{ml}), \mathrm{CL}(0.81 \pm 0.10 \mathrm{l} / \mathrm{h})$, and $\mathrm{V}_{\mathrm{z}}(1.29 \pm 0.12 \mathrm{l})$ of DIC in rats following p.o. administration were nearly equal to the corresponding values in rats following i.v. administration. The pharmacokinetic parameters of DIC determined in the present study are consistent with those reported in previous studies $(6,10-13)$. The $\mathrm{t}_{1 / 2}$ values of $1.22 \mathrm{~h}$ (i.v.) and $1.12 \mathrm{~h}$ (p.o.) for DIC in rats agree well with the reported $t_{1 / 2}$ values of $1.03 \mathrm{~h}$ in sheep (6), $1.3 \mathrm{~h}$ in dogs (10), and 1.04 and $1.12 \mathrm{~h}$ in 
humans $(11,12)$. In the present study, the MRT of DIC was $1.05 \mathrm{~h}$ following i.v. administration and $2.7 \mathrm{~h}$ following p.o. administration, whereas the CL of DIC was $0.6 \mathrm{l} / \mathrm{h}$ following i.v. administration and $0.81 \mathrm{l} / \mathrm{h}$ following p.o. administration; these values are very close to reported values in rabbits $\left(t_{1 / 2}\right.$, 1.30 and $2.68 \mathrm{~h}$; CL, 0.49 and $0.51 \mathrm{l} / \mathrm{h}$ ) (13). In comparison with rats, dogs, and sheep, a shorter $\mathrm{t}_{1 / 2}(5.15 \mathrm{~h})$ was observed in buffalo calves (6).

DIC is almost completely absorbed after p.o. It is subjected to first-pass metabolism in order that only approximately $50 \%$ of the drug reaches the systemic circulation in an unchanged form (13). This extensive metabolism is the reason for DIC having poor oral bioavailability. In previous studies, the bioavailability of DIC in sheep, rabbits, and humans was 50 , $50-60$, and $30 \%$, respectively $(6,12,13)$. In the present study, the bioavailability of p.o. DIC in rats was approximately $74.4 \%$. These results were markedly different from those of previous studies. The reasons for this remain to be elucidated in future studies. In most species, DIC is more than $99 \%$ protein bound (14-16), this property is responsible for its low $\mathrm{V}_{\mathrm{z}}(1.05$, i.v.; 1.29, p.o.) and CL (0.60, i.v.; 0.81, p.o.).

The present study revealed that p.o.administration induced a pronounced second peak in the plasma DIC concentration-time curve of rats; this second peak was not present following i.v. administration. The double-peak phenomenon has four typical causes: enterohepatic circulation, gastrointestinal circulation, delayed gastric emptying, and absorption differences in the intestines. We hypothesized that enterohepatic circulation was the main reason for the observed double-peak in the time-concentration curve of DIC in rats.

\section{Acknowledgements}

The present study was supported by the Yangtze Youth Fund (no. 2015cqn38) and the 2016 Undergraduate Innovation Experimental Project of Yangtze University (no. 2016043).

\section{References}

1. Todd PA and Sorkin EM: Diclofenac sodium. A reappraisal of its pharmacodynamic and pharmacokinetic properties, and therapeutic efficacy. Drugs 35: 244-285, 1988.
2. Imamura $\mathrm{H}$, Hata J, Iida A, Manabe $\mathrm{N}$ and Haruma K: Evaluating the effects of diclofenac sodium and etodolac on renal hemodynamics with contrast-enhanced ultrasonography: A pilot study. Eur J Clin Pharmacol 69: 161-165, 2013.

3. Armogida M and Gold M: Diclofenac potassium $25 \mathrm{mg}$ liquid capsules: Earlier and higher exposure to diclofenac. A fasted, single-dose, comparative bioavailability study vs. diclofenac potassium 2 x $12.5 \mathrm{mg}$ tablets. Int J Clin Pharmacol Ther 50: 445-451, 2012

4. Zeitlinger M, Rusca A, Oraha AZ, Gugliotta B, Müller M and Ducharme MP: Pharmacokinetics of a new diclofenac sodium formulation developed for subcutaneous and intramuscular administration. Int J Clin Pharmacol Ther 50: 383-390, 2012.

5. Zhai XJ, Yu Y, Chen F and Lu YN: Comparative bioavailability and tolerability of single and multiple doses of 2 diclofenac sodium sustained-release tablet formulations in fasting, healthy chinese male volunteers. Curr Ther Res Clin Exp 75: 53-58, 2013.

6. Rahal A, Kumar A, Ahmad AH and Malik JK: Pharmacokinetics of diclofenac and its interaction with enrofloxacin in sheep. Res Vet Sci 84: 452-456, 2008.

7. Shah VP, Midha KK, Findlay JW, Hill HM, Hulse JD, McGilveray IJ, McKay G, Miller KJ, Patnaik RN, Powell ML, et al: Bioanalytical method validation - a revisit with a decade of progress. Pharm Res 17: 1551-1557, 2000.

8. Karnes HT and March C: Precision, accuracy, and data acceptance criteria in biopharmaceutical analysis. Pharm Res 10: 1420-1426, 1993

9. Shen $X$ and Chen J: Certification of biological pharmaceutical analysis method. Chung Kuo Yao Hsueh Tsa Chih 24: 425-426, 1993.

10. Tsuchiya T, Terakawa M, Ishibashi K, Noguchi H and Kato R: Disposition and enterohepatic circulation of diclofenac in dogs. Arzneimittelforschung 30: 1650-1653, 1980.

11. Scallion R and Moore KA: Effects of food intake on the pharmacokinetics of diclofenac potassium soft gelatin capsules: A single-dose, randomized, two-way crossover study. Clin Ther 31: 2233-2241, 2009

12. Bedada SK, Yellu NR and Neerati P: Effect of resveratrol treatment on the pharmacokinetics of diclofenac in healthy human volunteers. Phytother Res 30: 397-401, 2016.

13. Kasperek R, Zimmer Ł, Jawień W and Poleszak E: Pharmacokinetics of diclofenac sodium and papaverine hydrochloride after oral administration of tablets to rabbits. Acta Pol Pharm 72: 527-538, 2015.

14. Sweetman SC and Martindale W: The Complete Drug Reference. 37th edition. The Pharmaceutical Press, London, 2011.

15. Willis JV, Kendall MJ, Flinn RM, Thornhill DP and Welling PG: The pharmacokinetics of diclofenac sodium following intravenous and oral administration. Eur J Clin Pharmacol 16: 405-410, 1979.

16. Fowler PD, Shadforth MF, Crook PR and John VA: Plasma and synovial fluid concentrations of diclofenac sodium and its major hydroxylated metabolites during long-term treatment of rheumatoid arthritis. Eur J Clin Pharmacol 25: 389-394, 1983. 